\title{
Estimation of riverbank soil erodibility parameters using genetic algorithm
}

\author{
TAPAS KARMAKER ${ }^{1, *}$ and RANJAN DAS ${ }^{2}$ \\ ${ }^{1}$ Department of Civil Engineering, Thapar University, Patiala 147004, India \\ ${ }^{2}$ School of Mechanical, Materials, and Energy Engineering, Indian Institute of Technology Ropar, \\ Rupnagar 140001, India \\ e-mail: tapas1976@gmail.com
}

MS received 7 May 2016; revised 23 January 2017; accepted 21 March 2017; published online 7 November 2017

\begin{abstract}
Determination of the erodibility parameters, such as critical shear stress and erodibility coefficient, are necessary before estimating the annual bank erosion (or bank retreat) at river reaches. However, in many cases, the river site is inaccessible making it difficult to assess the soil parameters either by in situ tests or by laboratory experiments. In this study, Genetic Algorithm (GA)-based optimisation technique was used to estimate the erodibility parameters of middle reaches of the Brahmaputra River in India. Two approaches were followed. At first, erodibility parameters were estimated using daily stage records at a selected site. Secondly, based on the annual observed bank erosions (bank retreat) from satellite images, erodibility parameters were estimated in three different river reaches. All these results were compared with that from a previous study using in situ jet tests. Annual bank erosions (bank retreat) were estimated using the median values of the erodibility parameters. The results agree well with the average observed annual bank erosion of these river reaches. In addition, the effects of measurement errors and optimisation algorithms on the parameter estimation were analysed. Sensitivity analysis of the parameters in GA was evaluated and it was found that GA can be utilised in the data-scarce regions to estimate the average erodibility parameters.
\end{abstract}

Keywords. Critical shear stress; erodibility coefficient; bank erosion; optimisation; Brahmaputra river.

\section{Introduction}

Riverbank erosion is of great concern as it leads to permanent loss of land and other valuable resources. Knowledge of prior erosion rate can save these resources and give sufficient time to act. It is well known that riverbank erosion primarily depends on soil erodibility parameters and the developed shear stress. The erodibility parameters include the critical shear stress and the erodibility coefficient. Critical shear stress can be defined as the limiting shear stress developed due to flowing water, if in excess, will lead to soil erosion. Hence, the erosion in either on the riverbank or the bed is assumed to be proportional to the excess shear stress and hence the erosion rate can be estimated by the following equation [1-3]:

$$
\varepsilon=k_{d}\left(\tau-\tau_{c}\right)^{a}
$$

where $\varepsilon$ is the rate of erosion $(\mathrm{m} / \mathrm{s}), k_{d}$ is the erodibility coefficient $\left(\mathrm{m}^{3} \mathrm{~N} / \mathrm{s}\right), \tau$ is the developed shear stress at the soil boundary $(\mathrm{Pa}), \tau_{c}$ is the critical shear stress $(\mathrm{Pa})$ and $a$ is the exponent, which is generally considered to be $1[4,5]$.
The shear stress developed can be accurately estimated using various methods such as the measured velocity profile near the bank [6] and the energy gradient method [7].

Alternatively, the average bank shear stress can also be estimated from the energy gradient method using the following equation [7]:

$$
\tau=0.76 \rho g D S
$$

where $\tau$ is the developed shear stress (Pa) at a depth $D$ from the free water surface $(\mathrm{m}), g$ is the gravitational acceleration $\left(\mathrm{m} / \mathrm{s}^{2}\right), S$ is the longitudinal slope of energy gradient line $\left(\mathrm{m} / \mathrm{m}^{1}\right)$ and assuming a uniform river flow, it is the longitudinal bed slope of the river.

The estimation of the erodibility parameters is very difficult due to the non-homogeneous nature of the soil. In the past few decades, researchers conducted extensive study to estimate erodibility parameters from the basic soil properties such as moisture content, soil structure, clay content or from chemical composition of soil pore water [8]. For example, Smerdon and Beasley [9] developed the following empirical equations to estimate the critical shear stress:

$$
\tau_{c}=0.16 \times\left(I_{w}\right)^{0.84}
$$

*For correspondence 


$$
\begin{gathered}
\tau_{c}=10.2 \times\left(D_{r}\right)^{-0.63} \\
\tau_{c}=3.54 \times 10^{-28.1 D_{50}} \\
\tau_{c}=0.493 \times 10^{0.0182 P_{c}}
\end{gathered}
$$

where $I_{w}$ is the plasticity index (\%), $D_{r}$ is the dispersion ratio (\%), $D_{50}$ is the median particle size $(\mathrm{m})$ and $P_{c}$ is the percent clay by weight (\%). Julian and Torres [10] developed an empirical critical shear stress equation based on percentage silt-clay $(S C,<0.63 \mathrm{~mm}$ ) content and given as follows:

$$
\begin{aligned}
\tau_{c}= & 0.1+0.1779(S C)+0.0028(S C)^{2}-2.34 \\
& \times 10^{-5}(S C)^{3}
\end{aligned}
$$

However, as the soil properties vary over a wide range and due to their dependency on several parameters, the erodibility parameters are very difficult to estimate $[8,11]$. The $S C$ method also does not give reliable results and differs significantly from in situ estimation as reported by Clark and Wynn [5]. Hence, this method was not utilised in this study. Alternatively, the critical shear stress can be estimated using flume studies, submerged jet test, rotating cylinder test and water tunnel test [5, 11, 12]. All the aforementioned methods have been well validated with the field results. Shields [13] prepared a diagram commonly known as Shields' diagram (SD) to estimate the critical shear stress for uniform, non-cohesive soils based on the sizes of sediment particles. However, the SD was modified later to find out the critical shear stress for the cohesive soils [14].

Furthermore, the estimation of erodibility parameters through flume study has some drawbacks. The main problem is that, it neither reproduces the erosion pattern of the field, nor the chemical composition of the water associated with erosion can be identified. There are various factors, for example, soil texture, structure, and water content, that can influence the erodibility of the cohesive soils [15]. Other factors such as freeze-thaw cycles and presence of plant roots can significantly modify the results [16]. Hence, in situ estimation through submerged jet test is the best alternative for this situation [1, 11]. Recent study done by Karmaker and Dutta [11] shows that the submerged jet test better estimates the erodibility parameters than other methods, and their results were also validated with actual observations in the Brahmaputra River. However, accessibility is the prime requirement for estimation of the erodibility parameters through submerged jet tests. A few locations are not accessible either by road or through river. Furthermore, the in situ results vary in a wide range and it is a time-consuming process. Numerous tests are required to obtain a reliable dataset. Hence, an alternative method that can produce acceptable results is essential. Even today, to the best of authors' knowledge, there is lack of inverse analysis for retrieving unknown parameters in bank erosion process. Therefore, this is a study to verify the applicability of inverse parameter estimation procedure for soil erodibility parameters. The present study investigated the following: (1) the suitability of the Genetic Algorithm (GA) optimisation technique for estimation of erodibility parameters based on the previous bank erosion records and hydrograph data and (2) the reliability and suitability of the results using this method in case of limited data availability.

\section{Study area}

The locations were selected along the Brahmaputra River in northeastern India (figure 1). Jamuguri (in the upper reach) $\left(26^{\circ} 50^{\prime} \mathrm{N}, 93^{\circ} 46^{\prime} \mathrm{E}\right), \quad$ Dolgobinda $\left(26^{\circ} 11^{\prime} \mathrm{N}, 93^{\circ} 41^{\prime} \mathrm{E}\right)$, Amingaon $\left(26^{\circ} 10^{\prime} \mathrm{N}, 91^{\circ} 41^{\prime} \mathrm{E}\right)$ and Nalbari (at the middle reach) $\left(26^{\circ} 27^{\prime} \mathrm{N}, 91^{\circ} 26^{\prime} \mathrm{E}\right)$ are the four sites considered for field-testing of the bank soil. The Brahmaputra River is known as a dynamic braided river, whose banks experience excessive erosion during monsoon. Significant morphological adjustment occurs in this river within a monsoon period [17]. The annual average rainfall is $\sim 1600 \mathrm{~mm}$ in this river basin [18]. The sizes of the riverbed materials do not vary and the mean size $\left(\mathrm{D}_{50}\right)$ is $\sim 0.20 \mathrm{~mm}$ [11]. Near the banks of Guwahati, there are small hilly formations; the soils of which are red colour and the $\mathrm{D}_{50}$ of the soil is $55 \mu \mathrm{m}$. In other places, the riverbanks are composed of alternative sand $\left(\mathrm{D}_{50}=0.2 \mathrm{~mm}\right)$ and silt layers $\left(\mathrm{D}_{50}=0.06 \mathrm{~mm}\right)$ [11]. The daily stage records were collected from the river gauging stations at Guwahati and Jamuguri from 2004 to 2007. Previous stage records of the Brahmaputra River reveal typical multiple flood waves during monsoon periods [19]. The Brahmaputra River typically shows near-vertical riverbanks [11]. This gives advantages to estimate the bank erosion directly from the bank retreat.

River bankline surveys were carried out using differential global positioning system (DGPS) made by TOPCON (Japan) with accuracy $<1 \mathrm{~cm}$ in 2007 (June to September) at various sites. Furthermore, by analysing multi-date satellite imagery, the bank lines of these sites in the previous years (2004-2006) were determined and the average bank erosion was estimated [20].

\section{Methodology}

The in situ estimation of the critical shear stress and the erodibility coefficient through submerged jet tests were measured as described by Hanson [3] and Hanson and Cook [4]. A total of 58 in situ submerged jet tests were carried out on the bank soils at various depths and locations to find the bank soil erodibility. The details of the tests were documented by Karmaker and Dutta [11]. The results indicated that the Brahmaputra bank soils fall under erodible to 


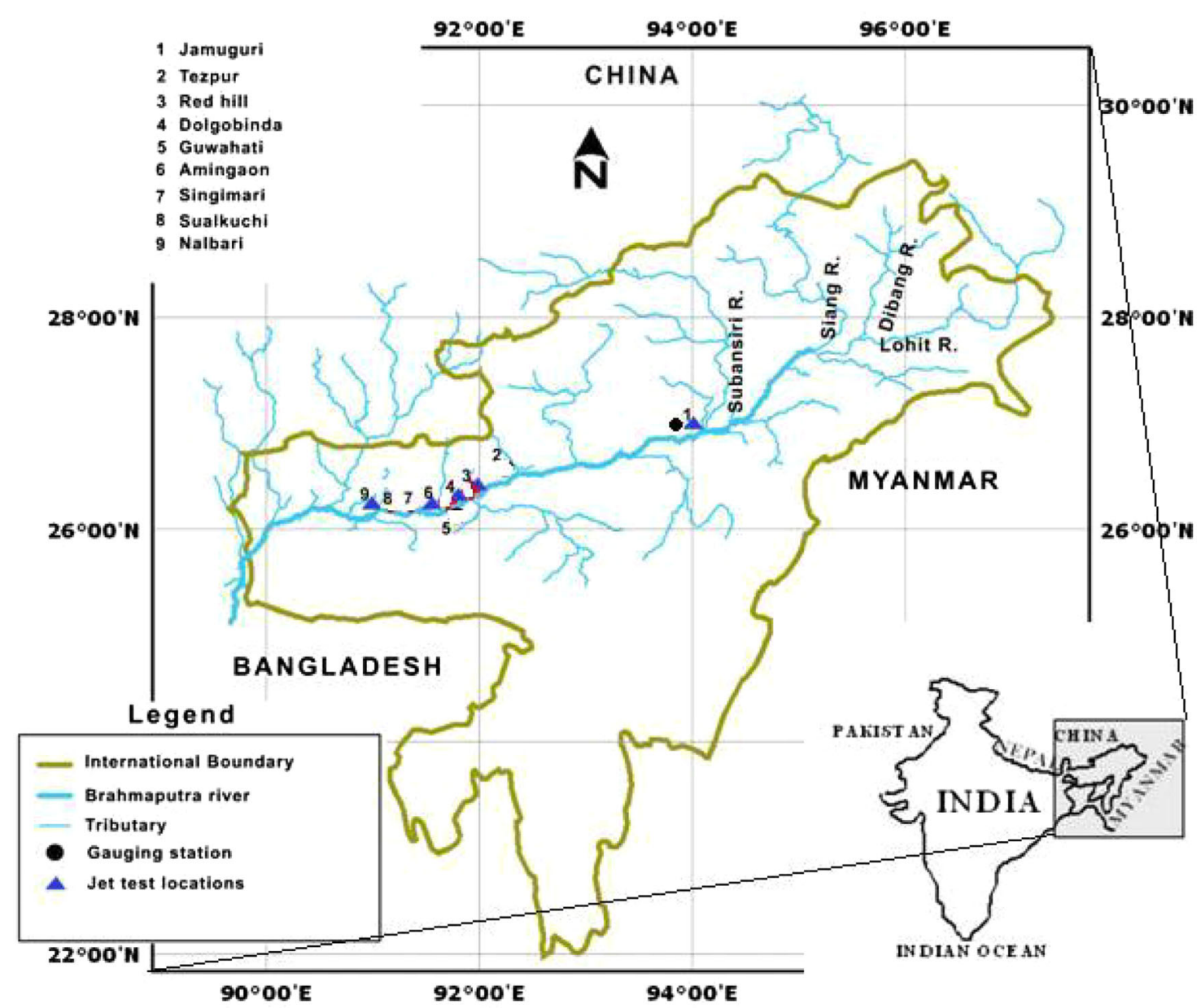

Figure 1. Study area in the North-East India showing the Brahmaputra River sites (modified from [11]).

highly erodible category with critical shear stress varying from 0.007 to $20.7 \mathrm{~Pa}$. The erodibility coefficient varies from 0.622 to $11.28 \mathrm{~cm}^{3}$ (N.s)

\subsection{Mathematical formulation}

The average bank shear stress developed was estimated using Eq. (2). In this equation, the flow depth was taken from the daily stage records as collected from the gauging stations. Bank erosion is estimated using Eq. (1). Variations in the daily stage in the rivers other than tidal rivers and flashy rivers are generally nominal [19]. Hence, for the estimation of daily bank erosion in the Brahmaputra River, the stage can be assumed as constant in a day. However, for successful modelling of the riverbank erosion, precise estimation of erodibility parameters are required [21].

The total erosion is the summation of the daily erosion over the monsoon season $(m)$. Therefore, the objective function can be formulated as follows:

$$
\text { Minimise (Error) : } \sum\left[E_{0}-E\right]^{2}
$$

where $E_{0}$ is the observed total erosion in the season (m). Seasonal bank erosion $(E)$ can be computed from the following equation:

$$
E=k_{d} \times\left(\tau-\tau_{c}\right) \times \Delta t
$$

where $\Delta t$ is the total time for fluvial erosion. Figure 2 shows the procedure to estimate the erodibility parameters as explained further:

1. At first, local river characteristics such as longitudinal slope, stage hydrographs or riverbank height, bankfull (or high flow) days are collected.

2. If stage hydrograph data are available, the shear stress developed is calculated using Eq. (2).

3. The GA optimisation is used to inversely estimate the parameters using Eqs. (1), (5) and (6).

4. If the stage hydrograph data are not available, then the approximate method is to collect the number of bank full days (or high flow days) either from previous stage records or from survey with local people. In addition, the average height of the riverbank is also required to be collected. 


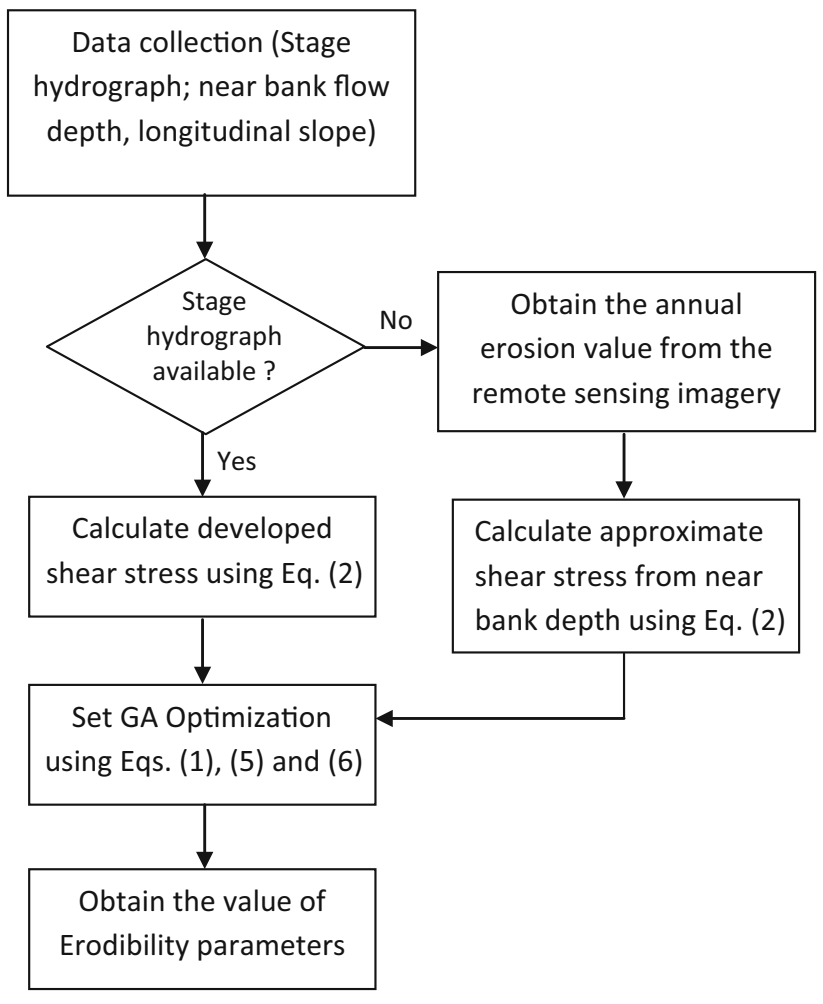

Figure 2. Flow chart to estimate the erodibility parameters using GA.

5. At this stage, Eq. (2) is used to find out the developed shear stress considering $D$ as the riverbank height. The $\Delta t$ in Eq. (6) can be substituted with the number of bankfull days or the high flow days.

\subsection{Bankline migration rate from multi-date satellite imagery}

The Landsat ETM satellite imagery of the study area was collected from the open source image database supported by Global Landuse and Cover Facility (GLCF). The yearly satellite images (February 2005; March 2006, May 2007, and November 2008) Panchromatic images (band 8) with $15 \mathrm{~m}$ spatial resolution at nadir) from ETM+ sensors of Landsat-7 satellite were stacked in a chronological order from 2005 to 2008 and the major channel bends were identified. The images were re-projected to the UTM projection system with WGS 84 ellipsoid zone 46-47. Georeferencing was carried out using image-to-image registering by considering the January 2004 image as the base. A minimum of 20 ground control points (GCPs) were collected for geo-referencing. All the images were based on the permanent features such as road junctions and important buildings. The second-order polynomial nearest-neighborhood resampling technique was used to correct the images [22]. The root mean square error was kept below 0.5 pixels.
In the corrected images, the annual bank lines were digitised manually. Furthermore, normalised difference water index (NDWI) data were calculated from red and green band data of the satellite images and the NDWI image was prepared to identify water and non-water zones. The digitised bank lines were overlaid on the NDWI image and checked for bankline accuracies. The annual bankline data were used to estimate the average bankline migration. The area between each pairs of subsequent years divided by the length of the bank line gives the average bankline migration. The riverbank retreat estimated from the satellite data was verified with the repeated bank line survey using DGPS. River bankline surveys were conducted twice every year: during high flow (June-July, water level nearly bankfull stage) and low flow (December) in 2007 and 2008. To verify the suitability of the optimisation, Jamuguri site was chosen for the present study. In this site, the collected daily stage records were used to estimate the developed shear stress in the bank. Using the GA-based optimisation technique, the erodibility parameters were determined. Previous records of the satellite imagery were used to find the average bank erosion of the site. For each year, five simulations were conducted. A total of 20 simulations were carried out to find the erodibility parameters of the bank soil in Jamuguri. The evaluated technique was further examined to find the suitability in estimating the erodibility parameters from the number of bankfull days [11]. The average bank erosions of two years (2007 and 2008) in three other sites (Nalbari, Dolgobinda, and Red hill soil) were used to evaluate the validity of the present method.

\subsection{GA optimisation}

The GA is an optimisation tool, which iteratively generates and tests a randomly selected group of possible solutions (termed as the population). The three main steps involved in GA are reproduction, cross-over and mutation. The process of reproduction initiates after generation of random initial population (group of feasible solutions) and evaluation of the fit is based on the value of the relevant objective function. The individuals (solutions) are updated and improved in the next generation. Subsequently, in the crossover operation, through an assigned probability (known as cross-over probability), randomly selected pairs from the old strings mate to produce new offspring. Therefore, the inferior old solutions (parents) are replaced by new solutions (children) in the subsequent generations. Next, the mutation operation is carried out in which, through an assigned probability (known as mutation probability), at some random locations, the genes (binary bits) in the string are changed. This process continues until a satisfactory fitness value of the objective function is attained, which occurs when the cumulative error reaches to $1 \times 10^{-8}$. In the present study, population size was taken as 50 , crossover fraction was 0.8 and the mutation probability was 
considered as 0.04. Further details about GA can be found in many studies [23-27] and hence, these are not repeated here.

Furthermore, in this study, two other optimisation algorithms were used to evaluate the erodibility parameters: (1) simulated annealing (SA) algorithm and (2) nonlinear programming (NLP) algorithm based on the interior point method. SA is an evolutionary optimisation algorithm mimicking the annealing process of heat treatment, where the objective function is initially assigned with some level (known as SA temperature, $T^{\prime}$ ) and is gradually minimised following an annealing schedule based on assigned probability levels. In SA using some initially guessed value, random solutions are generated and the differences of the objective functions between the initial guess and the new points $(e)$ are calculated. For a given point, if the error $e$ decreases, then that point is always accepted with the probability, $P=1$. However, if the error $e$ increases, then the acceptance of that point is based on the following condition,

$$
P=\exp \left(-e / T^{\prime}\right)
$$

More details about SA can be found elsewhere [28, 29], and hence these are not repeated here. Next, in NLP, which actually uses both the first- and second-order derivatives, for a given unknown, $n$, the Karush-Kuhn-Tucker (KKT) conditions are represented by the following Lagrangian function,

$$
£(n, \psi)=F(n)-\sum_{i=1}^{p} \psi_{i} j_{i}(n)
$$

where $\psi$ is the Lagrangian multiplier, $p$ is number of constraints and $j$ is the matrix of constraints, if any. For the present work, the constraints are governed by the range of parameters in which they are assumed to be located. Next, the KKT conditions are evaluated as follows:

$$
\begin{gathered}
\nabla_{n} £(n, \psi)=0 \\
\psi_{i} j_{i}(n)=0 ; \forall_{i=1}^{p} \\
j_{i}(n) \geq 0 \\
\psi_{i} \geq 0
\end{gathered}
$$

More details about the interior point-based NLP are available in many literatures [30-32]. Furthermore, since the estimation of the parameters depends on the exact measurement of bank erosion, it is essential to analyse the effect of errors in the measurement of bank erosion. In this study, $\pm 10 \%, \pm 15 \%$ and $\pm 20 \%$ error was considered in the total bank erosion measurements of Jamuguri site in each year.

Finally, the estimated soil parameters (median value) using GA were used to estimate the approximate yearly bank erosion in the river reaches along the Brahmaputra River.

\section{Results and discussions}

The estimation of erodibility parameters based on the field measurement of bank erosion is discussed in this section. The main focus of this section is to estimate various parameters, the effect of errors in the measurement of bank erosion, the sensitivity study of the parameters of the GA on the estimation of unknown parameters and the effect of other two optimisation algorithms on the estimation of the parameters.

\subsection{Effect of GA parameters on optimisation}

The GA results depend on various parameters among which population size, cross-over fraction and mutation probability are important. This section discusses the effect of these three parameters on the edibility parameter estimation. The population size of 10, 20, 40, 50, 80 and 100; Cross-over fraction of $0.5,0.8$ and 0.9 ; and uniform mutation probability of $0.01,0.03$ and 0.05 were considered for various cases (table 1). Results of iteration 1 in each case are shown in figure 3 . Results indicate that with the increase of population size, the erodibility parameters increase (figure 3a). However, the erodibility parameters decreased initially with the increase of cross-over fraction (figure $3 b$ ) and mutation probability (figure 3c). But the erodibility marginally increased afterwards in both the cases. This indicates that multiple combinations of parameters satisfying a given/prescribed objective exist for inverse problems [33]. Table 2 compares the influence of the population size of GA on the objective function value along with the elapsed computational times. For this comparison, the probabilities of cross-over and mutation are considered 0.80 and 0.01 , respectively. All computations have been done on Intel ${ }^{\circledR}$ Core(TM) i-3 3217U CPU with clock speed $1.8 \mathrm{GHz}$ and $4 \mathrm{~GB}$ RAM. The estimation has been done for predicting erodibility coefficient $k_{d}$ and

Table 1. Cases considered in estimation of erodibility parameters with various parameters in GA.

\begin{tabular}{lcccc}
\hline Case & Objective & $\begin{array}{c}\text { Population } \\
\text { size }\end{array}$ & $\begin{array}{c}\text { Cross over } \\
\text { fraction }\end{array}$ & $\begin{array}{c}\text { Mutation } \\
\text { probability }\end{array}$ \\
\hline 1 & Effect of & 10 & 0.8 & 0.01 \\
& population & 20 & & \\
size & 40 & & \\
& & 50 & & \\
& & 80 & & \\
& & 100 & & \\
& & 20 & 0.5 & 0.01 \\
& Effect of cross & & 0.8 & \\
& over fraction & & 0.9 & 0.01 \\
& Effect of & 20 & 0.8 & 0.03 \\
& mutation & & & 0.05 \\
\hline
\end{tabular}



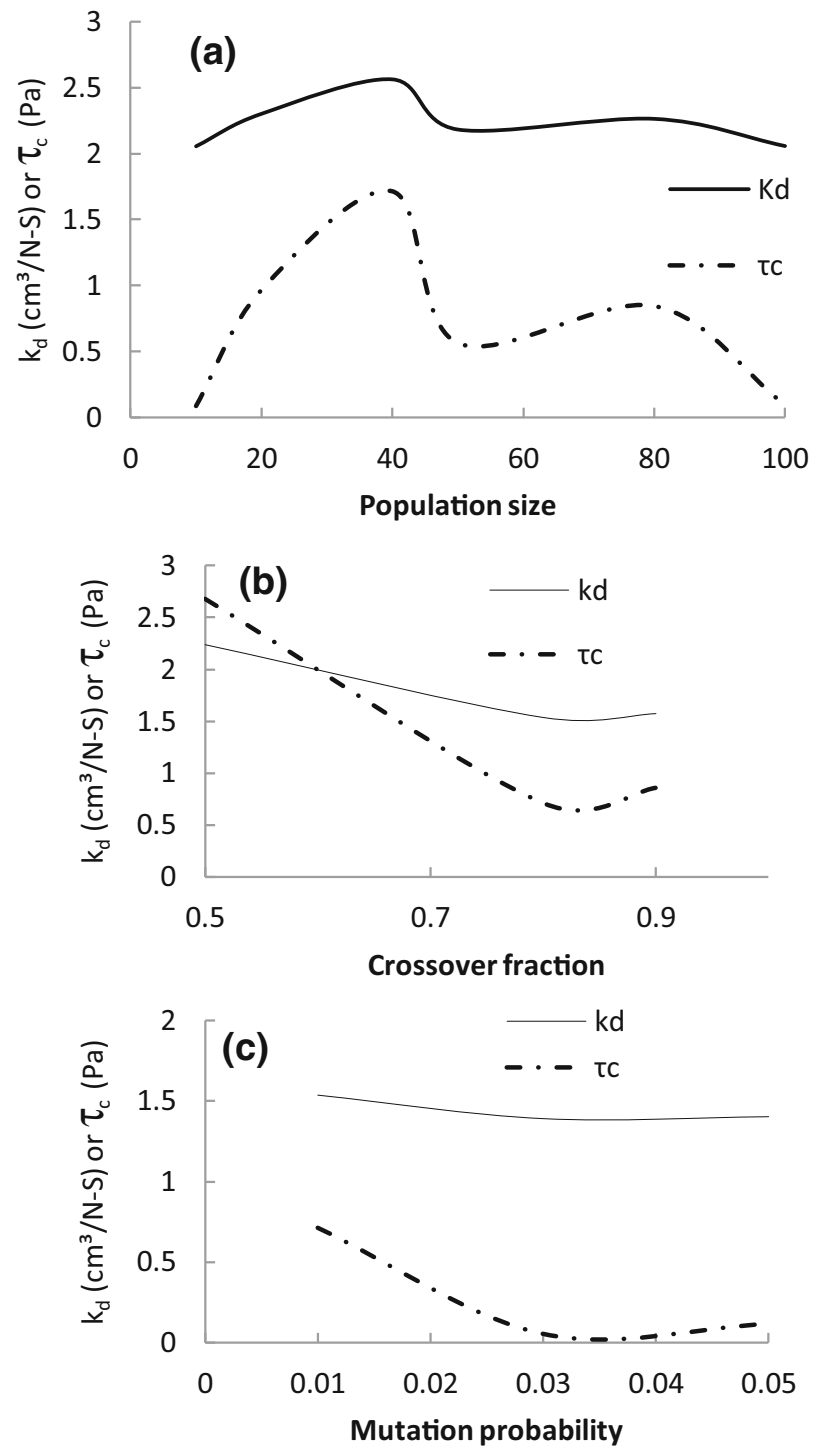

Figure 3. Effect of (a) population size, (b) cross over fraction, and (c) mutation probability on parameter estimation using GA.

Table 2. Effect of population size on objective function value and time of computation.

\begin{tabular}{lcr}
\hline Population size & Objective function value & Time (min) \\
\hline 10 & $6.54 \mathrm{E}-08$ & 9.93 \\
20 & $6.47 \mathrm{E}-09$ & 21.44 \\
40 & $5.31 \mathrm{E}-09$ & 42.30 \\
50 & $1.14 \mathrm{E}-09$ & 53.55 \\
80 & $1.11 \mathrm{E}-08$ & 81.50 \\
100 & $2.20 \mathrm{E}-09$ & 102.89 \\
\hline
\end{tabular}

critical shear stress $\tau_{c}$. It is apparent from the table that for all population sizes, the objective function values attain similar order of magnitudes. However, due to random searching, the accuracy of estimation does not necessarily improve as manifested between population sizes of 50 and 80. However, the CPU time considerably increases with increase of the population size. Therefore, for the present study, a population size of 50 has been selected because the least objective function value is observed corresponding to this size among the studied cases presented in table 2 .

From this study, the erodibility parameters were found to be almost independent of the GA parameters with the crossover fraction of 0.9 and mutation probability of 0.04 and these values were taken for further study. The stopping criteria are chosen either when the error function Eq. (5) becomes zero or the number of GA generations exceeds 50, which appears to be sufficient to decrease the objective function to a sufficient minimum value, $O\left(10^{-9}\right)$. It has been found that within these generations, the objective function value goes below $10^{-9}$, which is enough for this study.

\subsection{Parameter estimation at Jamuguri}

The parameters, critical shear stress and the erodibility coefficient were estimated at Jamuguri with observed stage records and seasonal bank erosion measurements. The critical shear stress and erodibility coefficients were estimated in lower $\left(0.001 \mathrm{~Pa}, 0.001 \mathrm{~cm}^{3}(\mathrm{~N}-\mathrm{s})^{-1}\right.$, respectively) and upper bounds $\left(25 \mathrm{~Pa}, 25 \mathrm{~cm}^{3}(\mathrm{~N}-\mathrm{s})^{-1}\right.$, respectively). Figure 4 shows the optimisation of the objective function with number of iterations without any measurement errors. For this simulation, about 40 iterations are found to attain the convergence. Notably, the number of iterations required to attain convergence vary from one simulation to another in case of GA. Figure 5a and b depicts the corresponding variation of the parameters with the number of iterations.

The plot between critical shear stress and erodibility coefficient using GA is shown in figure 6 . The figure shows the boundaries of various soil classes: highly resistant; resistant; moderately resistant; erodible and highly erodible. These boundaries are in accordance with the results by Hanson and Simon [12] and Karmaker and Dutta [11]. The figure indicates the bank soils falls under very erodible to erodible classes. Besides, the estimated erodibility parameter was in a similar range to that estimated previously with jet tests by Karmaker and Dutta [11]. To assess the significance between these two methods, one-dimensional analysis of variance (ANOVA) was carried out between the results as found by GA and jet tests (figure 7). Results show that the GA-based method of estimation gives almost a similar range for critical shear stress and erodibility coefficient. The median value of the critical shear stress was 4.8 $\mathrm{Pa}$ with jet tests and 4.0 $\mathrm{Pa}$ with GA. The erodibility coefficients were $4.2 \mathrm{~cm}^{3}(\mathrm{~N}-\mathrm{s})^{-1}$ and $2.7 \mathrm{~cm}^{3}(\mathrm{~N}-\mathrm{s})^{-1}$ for jet tests and GA, respectively. The results indicate that there is no significant difference between the means of the critical shear stress and the erodibility coefficients ( $p$ value for $\tau_{c}$ was 0.96 and for $k_{d}$ was 0.52 ). However, the ranges of the results for both the parameters in case of GA were less than that of jet tests. This difference is obvious due to the local variation of the soil during in situ jet tests. 


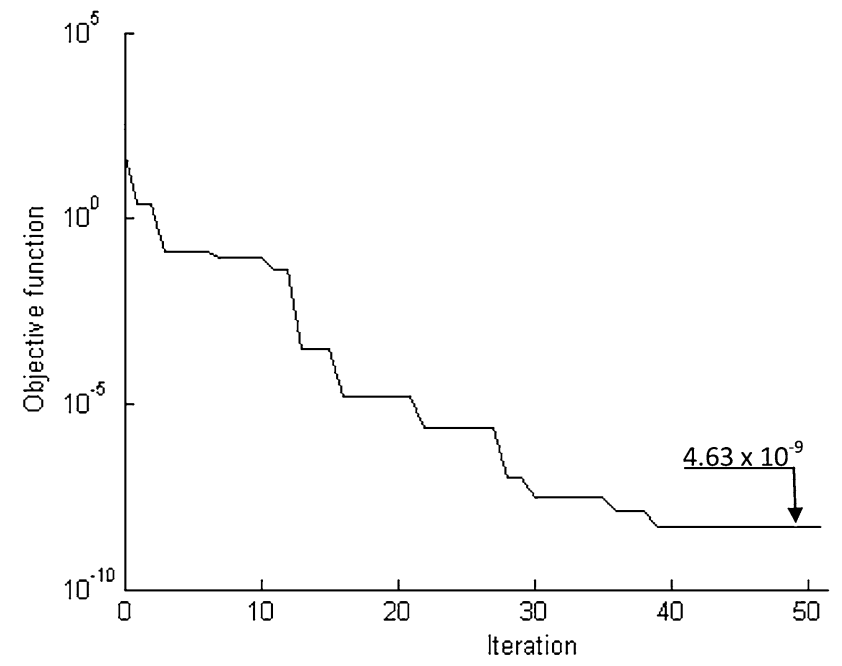

Figure 4. Objective function variation with the number of iterations.
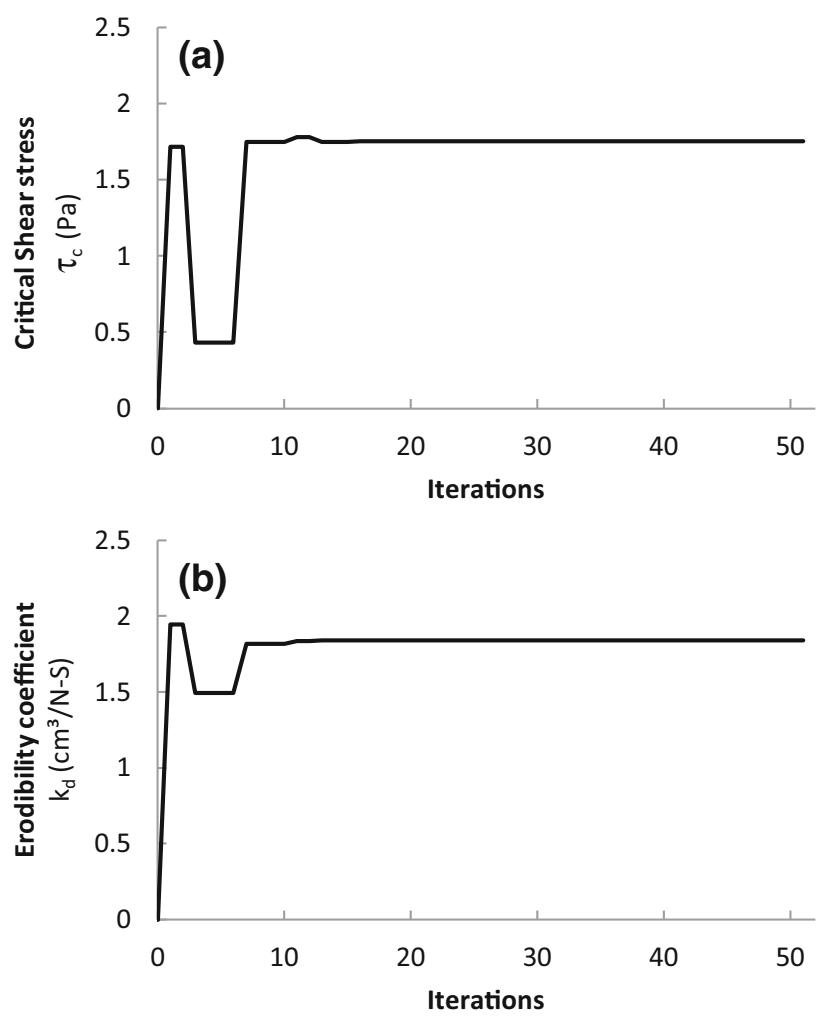

Figure 5. Variations of the (a) critical shear stress and (b) erodibility coefficients with iteration for the objective functions shown in figure 3.

\subsection{Effect of measurement errors on parameter estimation}

There are various methods to accurately measure the in situ bank erosion, e.g. analog erosion pin [34], photoelectric erosion pin [35] and repeated bank line survey with DGPS [18]. However, considering the spatial distribution of the riverbank erosion, it is often not possible to measure the bank erosion in situ. In that case, high-resolution satellite image (e.g., Landsat 7, ETM+ panchromatic sensors, $15 \mathrm{~m}$ spatial resolution) can be used to estimate the seasonal bank erosion. In this case, the bank erosion measurement contains different degrees of errors depending on the resolution and method applied to delineate the bank line. In this study, the estimation of the erodibility parameters is based on the erosion with $\pm 10 \%, \pm 15 \%$ and $\pm 20 \%$ errors (table 3 ). It was observed that in cases when the bank erosion is of a lower magnitude (cases 2 and 4), the objective functions converge satisfactorily in 50 iterations for errors $\pm 10 \%$ and $\pm 15 \%$. But with $\pm 20 \%$ erosion measurement, the objective function value failed to converge satisfactorily (Cases 2 and 4, table 3). However, in cases with higher magnitude of bank erosion (Cases 1 and 3), the objective function failed to converge even after 200th iterations for errors $\pm 15 \%$ or more. Hence, during a lower magnitude of annual bank erosion $(\sim 30 \mathrm{~m})$, this method can be considered to estimate the erodibility parameters satisfactorily with up to $\pm 15 \%$ error in erosion measurement.

\subsection{Effect of different algorithms of erodibility parameter estimation}

As discussed in the methodology section, two other optimisation algorithms (SA and NLP) were used to estimate the erodibility parameters for Jamuguri. In each case, 10 simulations were carried out. The SA algorithm found the erodibility coefficient with mean $1.99 \mathrm{~cm}^{3}(\mathrm{~N} \cdot \mathrm{s})^{-1}$ and standard deviation $0.33 \mathrm{~cm}^{3}(\mathrm{~N} \cdot \mathrm{s})^{-1}$, while the critical shear stress was estimated with mean $3.07 \mathrm{~Pa}$ and standard deviation $0.28 \mathrm{~Pa}$. The NLP algorithm found the erodibility coefficient with mean $4.46 \mathrm{~cm}^{3}(\mathrm{~N} \cdot \mathrm{s})^{-1}$ and standard deviation $2.80 \mathrm{~cm}^{3}(-$ $\mathrm{N} \cdot \mathrm{s})^{-1}$, while the critical shear stress was estimated with mean 6.52 $\mathrm{Pa}$ and standard deviation 1.28 Pa. Although the results of NLP are comparable up to a certain extent, the results of SA are far away from the jet test results. It was also found that the objective function values are much better in case of GA than any of these two methods. Hence, although many inverse methods are available, it was found in this study that GA gives better results with acceptable limit.

\subsection{Estimation of erodibility parameters at various sites}

Figure 8a-c shows the further results of the GA to test its suitability in case of lack of detailed stage records. As indicated by the figures, this method also seems to be suitable for estimating the average (or median) value of the erodibility parameters. In case of the soils from Dolgobinda site (figure 8a), the GA-estimated median critical shear stress $(4.5 \mathrm{~Pa})$ is higher than that estimated through jet tests (2.5 Pa). The critical shear stress data range is wide in jet 


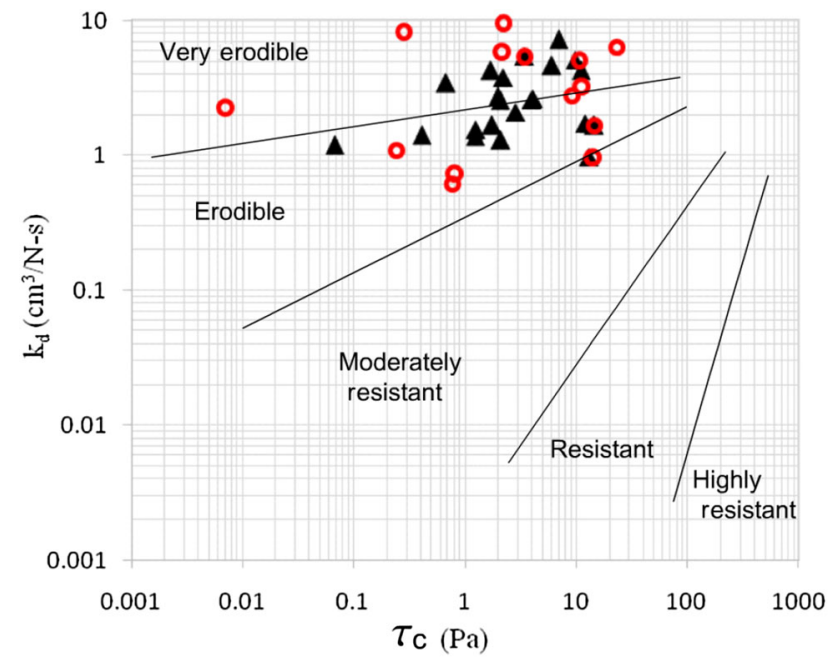

Figure 6. Classification of the river bank soil based on erodibility parameters (after Hanson and Simon 2001) [circle: Jet Test; Solid triangle: GA]. test. However, the median estimated erodibility coefficient by GA match closely with that by jet tests. The erodibility coefficient data ranges from 2.5 to $10 \mathrm{~cm}^{3}(\mathrm{~N} . \mathrm{s})^{-1}$. The range is at least two times higher than that by jet test. In Nalbari site (figure 8b), the GA (2.63 Pa) predicts lower $\tau_{c}$ as found by jet tests $(4.9 \mathrm{~Pa})$. The median of $k_{d}$ was lower through GA $\left(1.98 \mathrm{~cm}^{3}(\mathrm{~N} . \mathrm{s})^{-1}\right)$ than jet tests $\left(2.53 \mathrm{~cm}^{3}(-\right.$ N.s $)^{-1}$ ). The $p$ value indicates that the erodibility parameters through GA significantly match with the jet test results (table 4). Similar observations were also found in case of red hill soils (figure $8 \mathrm{c}$ ). In this case, $\tau_{c}$ was estimated lower by GA $(12.1 \mathrm{~Pa})$ than jet tests $(14.9 \mathrm{~Pa})$. The variations of data in jet tests are much higher than GA. However, the $k_{d}$ by GA significantly matches with the ranges as estimated by jet tests (table 4).

The discrepancy in the results can be seen as the jet method gives a direct measurement. The GA method can give multiple combinations of parameters to satisfy the same objective function. Moreover, the satellite method of
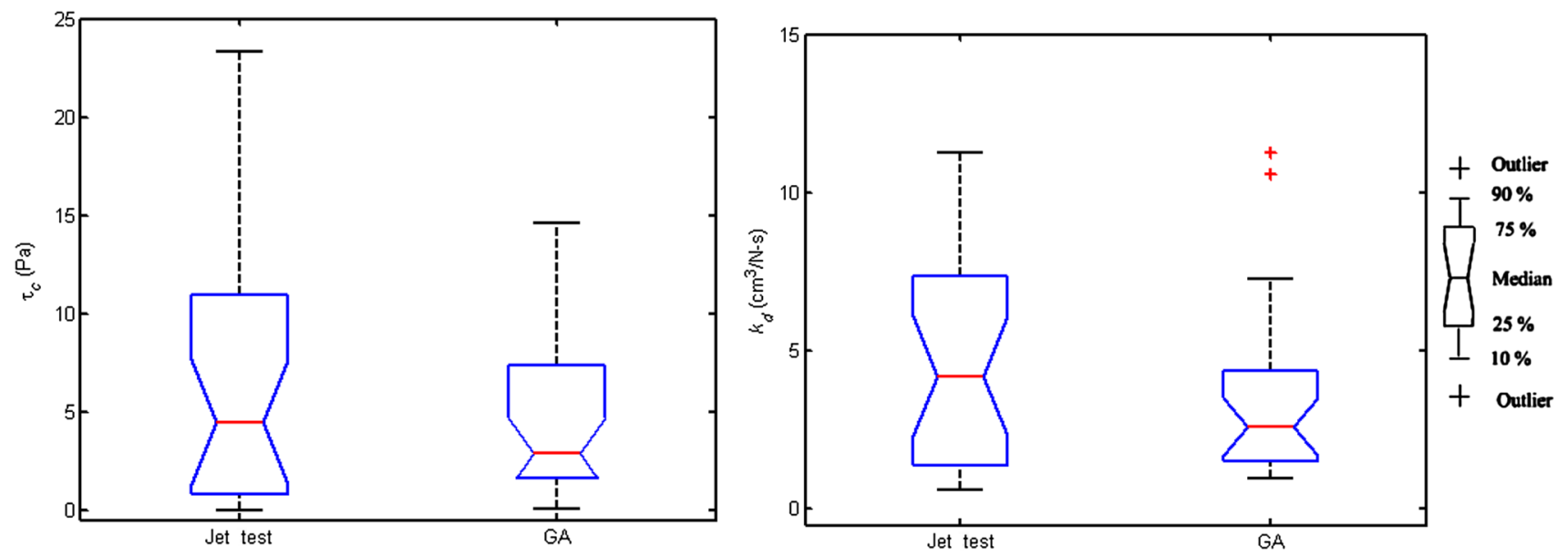

Figure 7. Comparison of erodibility parameters in Jamuguri, estimated from 2004 to 2007 year stage hydrograph.

Table 3. Estimation of erodibility parameters with measurement errors.

\begin{tabular}{|c|c|c|c|c|c|c|c|c|c|}
\hline \multirow[b]{2}{*}{ Case } & \multirow[b]{2}{*}{ Year } & \multirow[b]{2}{*}{ Observed average bank erosion $[\mathrm{m}]$} & \multirow[b]{2}{*}{ Error $(\%)$} & \multicolumn{2}{|c|}{$\begin{array}{c}\text { Erodibility } \\
\text { coefficient } \\
{\left[\mathrm{cm}^{3}(\mathrm{~N}-\mathrm{s})^{-1}\right]}\end{array}$} & \multicolumn{2}{|c|}{$\begin{array}{c}\text { Critical } \\
\text { shear } \\
\text { stress }[\mathrm{Pa}]\end{array}$} & \multicolumn{2}{|c|}{ Objective function value } \\
\hline & & & & -error & +error & -error & +error & -error & +error \\
\hline \multirow[t]{3}{*}{1} & 2005 & 197 & 10 & 2.094 & 2.427 & 1.047 & 0.651 & $2.40 \times 10^{-8}$ & $1.90 \times 10^{-6}$ \\
\hline & & & 15 & 2.183 & 2.676 & 1.729 & 1.053 & 0.99 & 14.23 \\
\hline & & & 20 & 1.827 & 3.133 & 0.991 & 1.839 & 8.27 & 22.87 \\
\hline \multirow[t]{3}{*}{2} & 2006 & 32 & 10 & 0.656 & 0.687 & 1.754 & 0.672 & $1.24 \times 10^{-15}$ & $1.91 \times 10^{-6}$ \\
\hline & & & 15 & 0.499 & 0.536 & 0.098 & 0.694 & $1.02 \times 10^{-11}$ & $3.44 \times 10^{-9}$ \\
\hline & & & 20 & 0.563 & 0.775 & 1.091 & 0.894 & 1.29 & 0.99 \\
\hline \multirow[t]{3}{*}{3} & 2007 & 110 & 10 & 1.339 & 0.997 & 0.949 & 0.001 & $9.25 \times 10^{-4}$ & $2.21 \times 10^{-5}$ \\
\hline & & & 15 & 0.921 & 0.951 & 0.001 & 0.009 & 195.86 & 1979.21 \\
\hline & & & 20 & 0.937 & 0.904 & 0.196 & 0.123 & 82.50 & 3034.12 \\
\hline \multirow[t]{3}{*}{4} & 2008 & 20 & 10 & 0.239 & 0.298 & 0.666 & 0.816 & $1.90 \times 10^{-4}$ & $8.25 \times 10^{-5}$ \\
\hline & & & 15 & 0.244 & 0.360 & 0.855 & 1.798 & 0.829 & $6.05 \times 10^{-4}$ \\
\hline & & & 20 & 0.308 & 0.282 & 0.623 & 0.307 & 0.11 & 0.30 \\
\hline
\end{tabular}



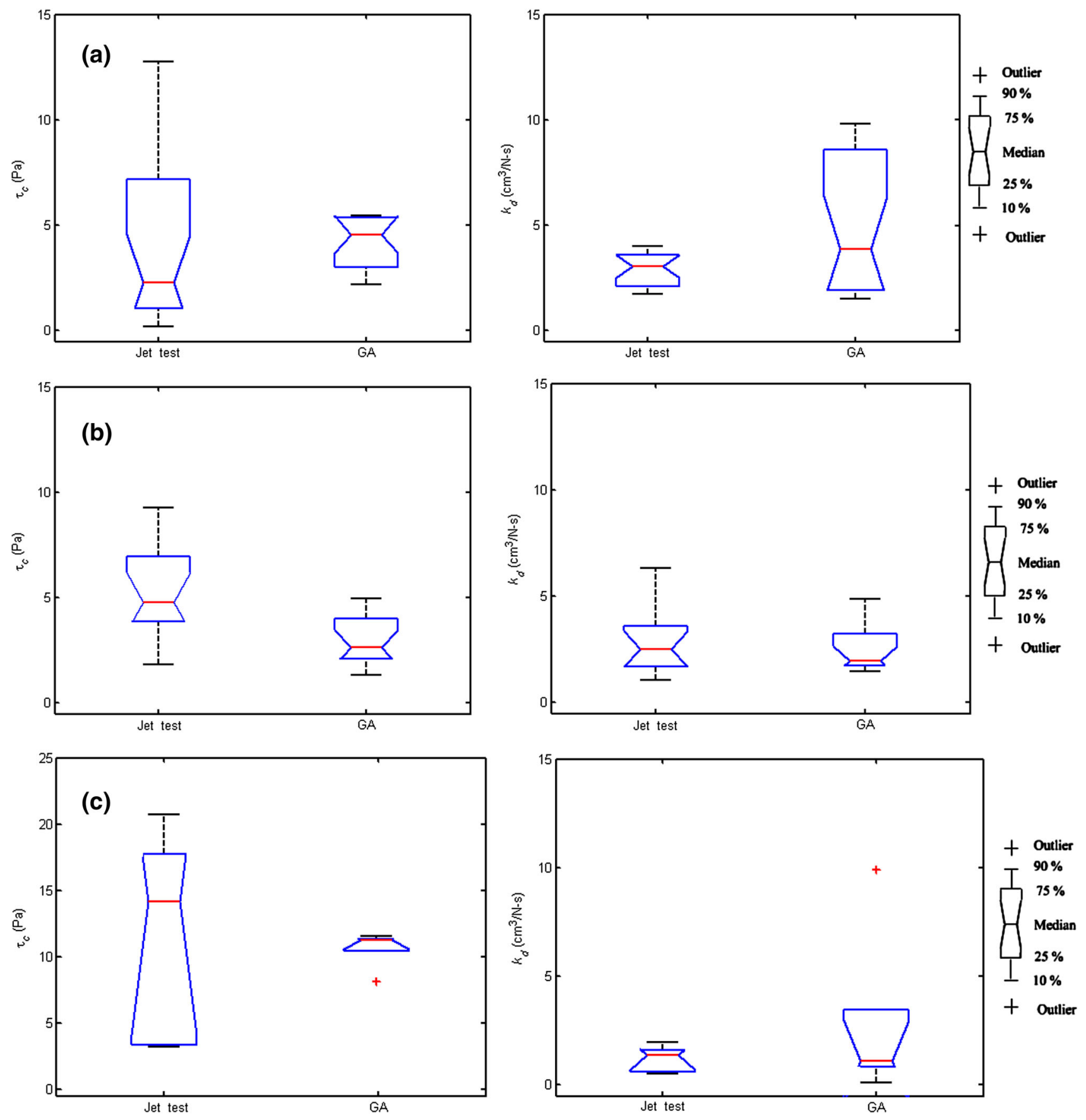

Figure 8. Comparison of erodibility parameters at (a) Dolgobinda, (b) Nalbari and (c) Red soil.

Table 4. Estimated $p$ values for different locations and parameters.

\begin{tabular}{lcc}
\hline Location & $p$ value for $\tau_{c}$ & $p$ value for $k_{d}$ \\
\hline Jamuguri & 0.96 & 0.52 \\
Dolgobinda & 0.81 & 0.02 \\
Nalbari & 0.06 & 0.78 \\
Red hill soil & 0.09 & 0.44
\end{tabular}

bank retreat estimate incorporates errors due to spatial resolutions. For this reason, the present study was carried out by incorporating the errors up to $20 \%$ to test the reliability of the method.

The aforementioned estimates of the erodibility parameters using GA indicate that the present method is very suitable to estimate the parameters in case of availability of daily stage records and the riverbed level records. The estimates in Jamuguri riverbank were examined for four 


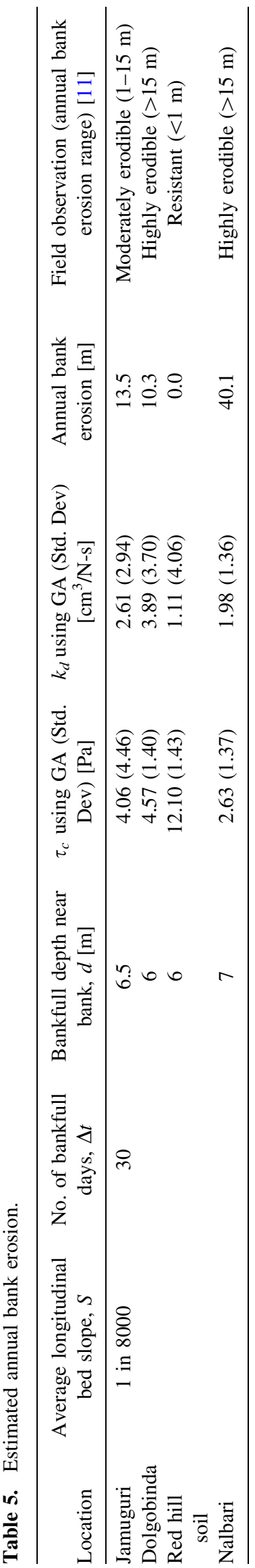

monsoon seasons from 2004 to 2007 . The median values of erodibility parameters were compared with the jet tests results performed by Karmaker and Dutta [11]. The GA method also gives satisfactory results in case of nonavailability of the daily stage records, which are very common in the developing countries. The minimum inputs to the model are approximate river bank depth, the bank erosion (retreat) rate and energy slope (or bed slope).

\subsection{Estimation of annual fluvial bank erosion}

In this case, the average annual erosion rate can be utilised to estimate the erodibility parameters. To verify the estimated parameters in predicting the annual bank erosion, the annual bank erosions were computed at four locations: Jamuguri, Dolgobinda, Nalbari and Red hill soils. Equation (8) was used to estimate the annual bank erosion. The estimated erosion results were compared with the results as observed by Karmaker and Dutta [11] in their study. Table 5 shows that results are comparable in GA. In case of Jamuguri, Red hill soil and Nalbari sites, the method predicted similar to the observed bank erosion. However, for Dolgobinda, the method slightly under-predicts the trend as observed by Karmaker and Dutta [11]. Hence, the method of estimating erodibility parameters through GA can be considered as suitable for data-scarce region.

\section{Conclusion}

In this present paper, three different optimisation algorithms were studied to estimate the erodibility parameters of the bank soil. Parametric study on GA-based optimisation technique was used to find the influence on estimation of erodibility parameters. The objective of this study was to find the suitability of this method in a data-scarce region. In the first case, the tests were carried out in a site where daily stage records were available. In the second case, the data were tested in three locations in absence of daily stage records. In the second case, the annual average erosion was taken to estimate the erodibility parameters. The results for both cases at all locations match well with the results as estimated by in situ jet tests. The results were compared using ANOVA analysis and it indicates that the results by both the methods to be significantly close.

Furthermore, results indicated that, during low magnitude of seasonal erosion $(<30 \mathrm{~m})$, the erodibility parameters can be estimated satisfactorily even with $15 \%$ error in the erosion measurement. However, during higher magnitude of seasonal erosion $(>110 \mathrm{~m})$, satisfactory estimation is not possible with error more than $10 \%$.

The main limitation is that, as in the inverse problem, multiple sets of solutions are possible for a specific result. So, at times, although both of the parameters are giving higher or lower order of estimation, a similar result can still 
be obtained. For this, a large number of solutions are required to be estimated and then the medium value can be taken. Future study can be conducted by using other optimisation technique such as NLP or other methods to estimate these parameters for better prediction.

Hence, it can be concluded that the method of GA can be effectively utilised in either the locations where the daily stage records are not available or the locations not easily accessible to conduct in situ jet tests. The analysis also indicates that the annual bank erosion can be predicted well using the results obtained by GA. The minimum inputs to the model are approximate river bank depth, bank erosion (retreat) rate and energy slope (or bed slope).

\section{References}

[1] Hanson G J and Cook K R 1997 Development of excess shear stress parameters for circular jet testing: ASAE. Paper No. 972227. St. Joseph, Mich.: ASAE, doi: 10.1002/esp.1657

[2] Hanson G J 1990a Surface erodibility of earthen channels at high stresses: Part I. Open channel testing. Trans. Am. Soc. Agric. Eng. 33(1): 127-131

[3] Hanson G J 1990b Surface erodibility of earthen channels at high stresses: Part II. Developing an in-situ testing device. Trans. Am. Soc. Agric. Eng. 33(1): 132-137

[4] Hanson G J and Cook K R 2004 Apparatus, test procedures, and analytical methods to measure soil erodibility in situ. Appl. Eng. Agric. 20(4): 455-462

[5] Clark L A and Wynn T M 2007 Methods for determining streambank critical shear stress and soil erodibility: implications for erosion rate predictions. Trans. Am. Soc. Agric. Biol. Eng. 50(1): 95-106

[6] Wilcock P R 1996 Estimating local bed shear stress from velocity observations. Water Res. Res. 32(11): 3361-3366

[7] Leutheusser H J 1963 Turbulent flow in rectangular ducts. $J$. Hydraul. Divis. ASCE 89: 1-19

[8] Grissinger E H 1982 Bank erosion in cohesive materials. In: Hey R D, Bathurst J C and Thorne C R (eds) Gravel-bed rivers. John Wiley \& Sons: New York, NY; 273-287

[9] Smerdon E T and Beasley R T 1961 Critical tractive forces in cohesive soils. Agric. Eng. 42(1): 26-29

[10] Julian J P and Torres R 2006 Hydraulic erosion of cohesive riverbanks. Geomorphology 76(1-2): 193-206

[11] Karmaker T and Dutta S 2011 Erodibility of fine soil from the composite river bank of Brahmaputra in India. Hydrol. Process. 25: 104-111

[12] Hanson G J and Simon A 2001 Erodibility of cohesive streambeds in the loess area of the Midwestern USA. Hydrol. Process. 15(1): 23-38

[13] Shields A 1936 Application of similarity principles and turbulence research to bed-load movement. Translated by Ott $\mathrm{W}$ $\mathrm{P}$ and van Uchelen J C (eds) California Institute of Technology, SCS Co-operative Laboratory: Pasadena, CA. 1-44

[14] Temple D M and Hanson G J 1994 Headcut development in vegetated earth spillways. Appl. Eng. Agric. 10(5): 677-682

[15] Grabowski R C, Droppo I G and Wharton G 2011 Erodibility of cohesive sediment: the importance of sediment properties. Earth-Sci. Rev. 105(1): 101-120
[16] Daly E R, Fox G A, Enlow H K, Storm D E and Hunt S L 2015 Site-scale variability of streambank fluvial erodibility parameters as measured with a jet erosion test. Hydrol. Process. 29: 5451-5464

[17] Karmaker T and Dutta S 2016 Prediction of short-term morphological change in large braided river using 2D numerical model. J. Hydraul. Eng. DOI: 10.1061/ (ASCE)HY.1943-7900.0001167

[18] Dutta B and Singh V P 2004 Hydrology. In: Singh V P, Sharma $\mathrm{N}$ and Ojha, C S P (Eds.), The Brahmaputra basin water resources. Kluwer Academic, the Netherlands, pp. 139-195

[19] Karmaker T and Dutta S 2010 Generation of synthetic flood hydrograph in a large river basin. J. Hydrol. 381(3-4): 287-296

[20] Karmaker T 2010 Modeling of bank erosion in a composite riverbank in alluvial river bend. Unpublished Ph.D. thesis, Indian Institute of Technology Guwahati, Assam, India. pp 200

[21] Karmaker T and Dutta S 2015 Stochastic erosion of composite banks in alluvial river bends. Hydrol. Process. 29(6): 1324-1339

[22] Lillesand M T, Kiefer R W and Chipman J W 2008 Digital image interpretation and analysis. Remote sensing and image interpretation. 6th edn, India, Wiley, 487

[23] Whitley D 1994 A genetic algorithm tutorial. Statist. Comput. 4(2): 65-85

[24] Deb K 1995 Optimization for engineering design, algorithms and examples, Prentice-Hall India Pvt. Ltd, New Delhi, India

[25] Houck C R, Joines J A and Kay M G 1995 A genetic algorithm for function optimization: a Matlab implementation. NCSU-IE TR, 95(09)

[26] Weile D S and Eric M 1997 Genetic algorithm optimization applied to electromagnetics: a review. IEEE Trans. Antennas Propag. 45(3): 343-353

[27] Das R 2012 Application of genetic algorithm for unknown parameter estimations in cylindrical fin. Appl. Soft Comput. 12(1): 3369-3378

[28] Kirkpatrick S, Gelatt Jr C D and Vecchi M P 1983 Optimization by simulated annealing. Science 220: 671-680

[29] Das R and Ooi K T 2013 Application of simulated annealing in a rectangular fin with variable heat transfer coefficient. Inverse Probl. Sci. Eng. 21(8): 1352-1367

[30] Coleman T F and $\mathrm{Li} \mathrm{Y} 1996$ An interior, trust region approach for nonlinear minimization subject to bounds. SIAM J. Optimiz. 6: 418-445

[31] Byrd R H, Hribar M E and Nocedal J 1999 An interior point algorithm for large-scale nonlinear programming. SIAM J. Optimiz. 9: 877-900

[32] Nocedal J and Wright S J 2006 Numerical optimization, 2nd edn, Springer Series in Operations Research, Heidelberg: Springer Verlag

[33] Das R and Ooi K T 2013 Predicting multiple combination of parameters for designing a porous fin subjected to a given temperature requirement. Energy Conserv. Manag. 66: 211-219

[34] Lawler D M 1993 The measurement of river bank erosion and lateral channel change: a review. Earth Surface Process. Landforms 18(9): 777-821

[35] Lawler D M 1991 A new technique for the automatic monitoring of erosion and deposition rates. Water Resour. Res. 27: 2125-2128 